\title{
INCIDENCE OF MACULAR CYSTOID EDEMA AFTER CATARACT SURGERY WITH OPTICAL COHERENCE TOMOGRAPHY EXAMINATION AT H. ADAM MALIK MEDAN HOSPITAL AND Dr. PIRNGADI MEDAN HOSPITAL
}

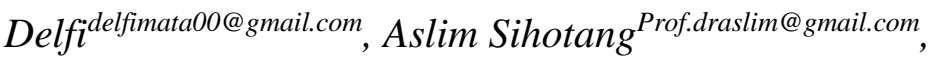 \\ M. Syukri Hamonangan ${ }^{\text {msyukrihamonangan@gmail.com }}$
}

\begin{abstract}
Background: Post cataract surgery macular cystoid edema or Irvine-Gass syndrome is cystoid macular edema (CME) that occurs after cataract surgery. Optical coherence tomography (OCT) will show the extensive retinal thickening with an image of cysts (low reflectivity) in the inner nuclear layer and outer plexiform layers.

Purpose: To determine the incidence of macular cystoid edema after cataract surgery and to provide an overview of the factors that have potential to cause CME by examining optical coherence tomography (OCT) in Haji Adam Malik Medan hospital and Dr. Pirngadi Medan hospital.

Methods: This research is a descriptive observational prospective design. Post cataract surgery macular cystoid edema is examined with Optical Coherence Tomography (OCT).

Result: There was not found post cataract surgery macular cystoid edema. There were significant differences in mean macula thickness after cataract surgery based on the type of surgery. There was an increase in mean macula thickness in ECCE technique cataract surgery with iris trauma and the rest of the lens cortex. There was no significant difference in mean post cataract surgery macular thickness based on age, history of hypertension and diabetes mellitus

Conclusion: There was no post cataract surgery cystoid macular edema. There was a significant difference in the mean macular thickness after cataract surgery based on the type of surgery, an increase in the mean macular thickness in ECCE cataract surgery with iris trauma and the remains of the lens cortex and there was no significant difference in the mean macular thickness. post cataract surgery based on age, history of hypertension and diabetes mellitus
\end{abstract}

Key Word: Irvine-Gass syndrome, Optical coherence tomography (OCT), mean macular thickness. 


\section{Introduction}

Macular cystoid edema or cystoid macular edema (CME) is a common pathological complication of the retina and it is present in a variety of pathological conditions such as inflammation in the eyeball, central or branch retinal vein occlusion, diabetic retinopathy, and most commonly after cataract surgery. (Rotsos TG, Moschos MM,2008).

Post cataract surgery cystoid macular edema or post cataract extraction cystoid macular edema, also known as Irvine-Gass syndrome is cystoid macular edema that occurs after cataract surgery. (Jackson TL,2008; Rotsos TG, Moschos MM,2008). Irvine-Gass syndrome is divided into: CME angiography and CME clinical. CME angiography is CME without symptoms and it is detected only through fluorescein angiography or optical coherence tomography (OCT). Clinical CME is CME with visual impairment symptoms, usually 20/40 or less. (American Academy of Ophthalmology,2011-2012).

CME angiography occurs in 40-70\% after ICCE surgery and approximately 1-19\% after ECCE surgery or phacoemulsification. Clinical CME incidence is 2-10\% after ICCE and 1-2\% after ECCE with intact posterior capsules. The risk of clinical CME after phacoemulsification with whole posterior capsules is lower. (American Academy of Ophthalmology,2011-2012).

The study of Ah Fat, et al reported that cataract surgery with vitreous loss caused CME complications in $30.8 \%$ of 39 eyes with ECCE surgery and $18.7 \%$ of 48 patients had phacoemulsification surgery. (Ah Fat, et al., 1998).

\section{Methods}

This research is a descriptive observational prospective design by taking data from patients at Haji Adam Malik Medan Hospital and Dr. Pirngadi Medan Hospital in 2015.The study population was taken from patients who received cataract surgery (phacoemulsification and ECCE) and visited the ophthalmology polyclinic of Haji Adam Malik Medan hospital and Dr.Pirngadi Medan hospital. The sample size was determined by consecutive sampling method, with a minimum number of 24 people.

\section{Result}


The research subjects were the patients who underwent the cataract surgery at the $\mathrm{H}$. Adam Malik General Hospital and Dr.Pirngadi Regional Hospital Medan in January-August 2015. The total number of research subjects was 24 people (48 eyes), of which 12 people (24 eyes) underwent the cataract surgery with phacoemulsification technique performed by the ophthalmologist and 12 people (24 eyes) underwent the cataract surgery with extra capsular cataract extraction (ECCE) technique performed by the ophthalmologist and ophthalmology resident.

Table 1. Patient Demographic

\begin{tabular}{ccccc} 
Patient Demographic & \multicolumn{2}{c}{ Phacoemulsifaction Technique } \\
Value & ECCE Technique Value \\
\hline n & $\%$ & N & $\%$
\end{tabular}

\section{Gender}

\begin{tabular}{llccc}
\multicolumn{1}{c}{\begin{tabular}{l} 
Male \\
\multicolumn{1}{c}{ Female }
\end{tabular}} & 8 & $66,7 \%$ & 8 & $66,7 \%$ \\
\hline Age & 4 & $33,3 \%$ & 4 & $33,3 \%$ \\
$18-40$ years old & 2 & $16,7 \%$ & 0 & $0 \%$ \\
$41-60$ years old & 3 & $25 \%$ & 3 & $25 \%$ \\
$61-80$ years old & 7 & $58,3 \%$ & 8 & $66,7 \%$ \\
$\quad>80$ years & 0 & $0 \%$ & 1 & $8,3 \%$ \\
old & & $33,3 \%$ & 0 & $0 \%$ \\
\hline $\begin{array}{l}\text { History of } \\
\text { Hypertension }\end{array}$ & 4 & $33,3 \%$ & 0 & $0 \%$ \\
\hline $\begin{array}{l}\text { History of Diabetes } \\
\text { Mellitus }\end{array}$ & 4 & & & \\
\hline
\end{tabular}

In Table 1, it shows the distribution of the characteristics of research subjects who underwent the cataract surgery of phacoemulsification technique and ECCE technique. Where the largest number of subjects who underwent the cataract surgery of phacoemulsification technique aged 61-80 years are 7 people (58.3\%),8 people are male 
(66.7\%), 4 people had a history of hypertension (33.3\%), and 4 people had a history of diabetes mellitus (33.3\%). And the largest number of subjects who underwent the cataract surgery of ECCE technique aged 61-80 years are 8 people $(66.7 \%), 8$ people are male $(66.7 \%)$ and no one had a history of hypertension and diabetes mellitus $(0 \%)$.

Table 2a. Preoperative Visual Acuity of Cataract Patients

\section{Visual Acuity}

Surgery Technique

Total

\begin{tabular}{lccccccc} 
& \multicolumn{2}{c}{$1 / \sim-3 / 60$} & \multicolumn{2}{c}{$4 / 60-5 / 50$} & \multicolumn{2}{c}{$>5 / 50$} & \\
\cline { 2 - 7 } & $\mathrm{n}$ & $\%$ & $\mathrm{n}$ & $\%$ & $\mathrm{~N}$ & $\%$ & \\
\hline Phacoemulsification & 10 & 83,4 & 1 & 8,3 & 1 & 8,3 & 12 \\
ECCE & 12 & 100 & 0 & 0 & 0 & 0 & 12 \\
Total & 22 & 91,6 & 1 & 4,2 & 1 & 4,2 & 24 \\
\hline
\end{tabular}

In Table 2, shows the preoperative visual acuity of cataract patients who underwent the cataract surgery with phacoemulsification and ECCE technique. Among the 12 people who underwent the cataract surgery with phacoemulsification technique, 10 people had 1/ - 3/60 of visual acuity $(83,4 \%)$. And all of the 12 people who underwent the cataract surgery with ECCE technique had 1/ - 3/60 visual acuity (100\%).

Table 2b. Visual Acuity of Patients in Week 12 of The Postoperative Cataract Surgery

\begin{tabular}{|c|c|c|c|c|c|c|c|}
\hline \multirow{3}{*}{ Surgery Technique } & \multicolumn{4}{|c|}{ Visual } & & & \multirow{3}{*}{ Total } \\
\hline & \multicolumn{2}{|c|}{$\begin{array}{l}\text { Acu } \\
<5 / 50\end{array}$} & \multicolumn{2}{|c|}{$5 / 50-5 / 16$} & \multicolumn{2}{|c|}{$5 / 16-5 / 5$} & \\
\hline & $\mathrm{n}$ & $\%$ & $\mathrm{n}$ & $\%$ & $\mathrm{n}$ & $\%$ & \\
\hline Phacoemulsification & 0 & 0 & 0 & 0 & 12 & 100 & 12 \\
\hline ECCE & 0 & 0 & 2 & 16,6 & 10 & 83,4 & 12 \\
\hline Total & 0 & 0 & 2 & 8,4 & 22 & 91,6 & 24 \\
\hline
\end{tabular}

In Table 2b, shows that all patients who underwent the cataract surgery of phacoemulsification technique had 5/16 - 5/5 of visual acuity $(100 \%)$. The patients who 
underwent the cataract surgery of ECCE technique,10 people had 5/16 - 5/5 of visual acuity (83.4\%) and 2 people had 5/50 - 5/16 visual acuity (16.6\%).

Table 3. Cystoid Macular Edema (CME) and Inflammation of the Anterior Chamber in Postoperative Cataract Surgery

\section{Cataract Surgery}

$(\mathbf{n}=\mathbf{2 4})$

Phacoemulsification

ECCE

$(\mathrm{n}=12) \quad(\mathrm{n}=12)$

\begin{tabular}{lllll}
$\mathrm{n}$ & $\%$ & $\mathrm{n}$ & $\%$ \\
\hline
\end{tabular}

Cystoid Macular Edema

(CME)

\begin{tabular}{rccrr} 
Yes & 0 & 0 & 0 & 0 \\
No & 12 & 100 & 12 & 100 \\
\hline
\end{tabular}

\section{Inflammation of the}

Anterior Chamber

\begin{tabular}{ccccc} 
Yes & 0 & 0 & 0 & 0 \\
No & 12 & 100 & 12 & 100 \\
\hline
\end{tabular}

In Table 3, shows that all patients who underwent the cataract surgery with phacoemulsification and ECCE technique didn't have CME and Inflammation of the anterior chamber. 
Table 4. Posterior Capsular Rupture and Intraocular Lens Placement during Cataract Surgery

\section{Cataract Surgery $(n=24)$}

Phacoemulsification

$$
(\mathrm{n}=12)
$$

Posterior Capsular Rupture

Yes

0

No

12

\section{Intraocular Lens Placement}

Anterior chamber

Posterior chamber
$\mathrm{N}$

0

$$
(\mathrm{n}=12)
$$

$\%$

0

0

0

100

0

0

0

\begin{tabular}{lllll} 
Posterior chamber & 12 & 100 & 12 & 100 \\
\hline
\end{tabular}

ECCE

$(n=12)$

In Table 4, shows that during the cataract surgery with phacoemulsification and ECCE technique, no patients had posterior capsular rupture. The intraocular lens of all patients placed in the posterior chamber during the cataract surgery with phacoemulsification and ECCE technique (100\%).

Table 5. The Mean of Macular Thickness after Cataract Surgery with Phacoemulsification and ECCE Technique

\begin{tabular}{lccc}
\hline & \multicolumn{2}{c}{ Cataract Surgery } \\
& \multicolumn{2}{c}{$(\mathbf{n = 2 4 )}$} & \\
\cline { 2 - 3 } & $\begin{array}{c}\text { Phacoemulsification } \\
(\mathrm{n}=12)\end{array}$ & $\begin{array}{c}\text { ECCE } \\
(\mathrm{n}=12)\end{array}$ & \\
& $\mathrm{x} \pm \mathrm{SD}$ & $\mathrm{x} \pm \mathrm{SD}$ & \\
\hline Week 1 & $212.00 \pm 13.59$ & $237.25 \pm 8.95$ & 0.001 \\
Week 2 & $221.08 \pm 11.26$ & $241.75 \pm 9.16$ & 0.001 \\
Week 4 & $226.08 \pm 7.69$ & $245.25 \pm 8.49$ & 0.001 \\
Week 8 & $229.33 \pm 4.52$ & $253.42 \pm 13.02$ & 0.001 \\
Week12 & $224.92 \pm 8.26$ & $247.67 \pm 10.71$ & 0.001 \\
\hline
\end{tabular}


In Table 5, shows that the mean of macular thickness after cataract surgery with phacoemulsification technique from week $1,2,4,8$, and 12 are $212.00 \pm 13.59 ; 221.08 \pm 11.26$; $226.08 \pm 7.69 ; 229.33 \pm 4.52 ; 224.92 \pm 8.26$. The average of macular thickness after cataract surgery with ECCE technique from week 1,2,4,8, and 12 are 237.25 \pm 8.95; $241.75 \pm 9.16$; $245.25 \pm 8.49 ; 253.42 \pm 13.02 ; 247.67 \pm 10.71$. Based on the $T$ test $\mathrm{p}=0.001(\mathrm{p}<0.05)$ showed a significant difference in the mean of macula thickness after cataract surgery between phacoemulsification and ECCE technique in week 1,2,4,8,and 12.

Table 6. The Mean of Macular Thickness based on Iris Trauma a.Phacoemulsification Technique

\section{Iris Trauma $(\mathbf{n}=12)$}

$\begin{array}{lcc} & \begin{array}{c}\text { Yes }(\mathrm{n}=0) \\ \mathrm{x} \pm \mathrm{SD}\end{array} & \mathrm{No}(\mathrm{n}=12) \\ \mathrm{x} \pm \mathrm{SD}\end{array}$

b.ECCE Technique

\begin{tabular}{cccc}
\hline & \multicolumn{2}{c}{ Iris Trauma $(\mathbf{n = 1 2})$} & \\
& $\begin{array}{c}\text { Yes }(\mathrm{n}=5) \\
\mathrm{x} \pm \mathrm{SD}\end{array}$ & $\begin{array}{c}\text { No }(\mathrm{n}=7) \\
\mathrm{x} \pm \mathrm{SD}\end{array}$ & $\boldsymbol{p}$ Value \\
\hline Week 1 & $254.60 \pm 18.75$ & $211.14 \pm 7.73$ & 0.005 \\
Week 2 & $246.40 \pm 18.69$ & $230.29 \pm 25.48$ & 0.259 \\
Week 4 & $254.20 \pm 23.99$ & $223.00 \pm 22.65$ & 0.045 \\
Week 8 & $257.60 \pm 24.91$ & $234.43 \pm 24.77$ & 0.142 \\
Week 12 & $251.40 \pm 12.75$ & $240.57 \pm 26.44$ & 0.421 \\
\hline
\end{tabular}

In Table 6a, shows that no iris trauma happened during cataract surgery with phacoemulsification.In Table $6 \mathrm{~b}$, based on the T test $\mathrm{p}=0.005(\mathrm{p}<0.05)$ and $\mathrm{p}=0.045(\mathrm{p}<0.05)$ 
showed significant difference in the mean of macula thickness between the iris trauma and no iris trauma in the first and the fourth week after the ECCE surgery.

Table 7. The Mean of Macular Thickness based on The Remains of Lens Cortex Fragments a.Phacoemulsification Technique

\begin{tabular}{|c|c|c|}
\hline & \multicolumn{2}{|c|}{$\begin{array}{c}\text { Remains of Lens Cortex Fragments } \\
(n=12)\end{array}$} \\
\hline & $\begin{array}{c}\text { Yes }(n=0) \\
x \pm S D\end{array}$ & $\begin{array}{c}\text { No }(n=12) \\
x \pm S D\end{array}$ \\
\hline Week 1 & 0 & $212.00 \pm 13.59$ \\
\hline Week 2 & 0 & $221.08 \pm 11.26$ \\
\hline Week 4 & 0 & $226.08 \pm 7.69$ \\
\hline Week 8 & 0 & $229.33 \pm 4.52$ \\
\hline Week 12 & 0 & $224.92 \pm 8.26$ \\
\hline
\end{tabular}

b.ECCE Technique

\begin{tabular}{cccc}
\hline & \multicolumn{2}{c}{ Remains of Lens Cortex Fragments } \\
$(\mathbf{n = 1 2})$ & No $(\mathrm{n}=7)$ & p Value \\
& Yes $(\mathrm{n}=5)$ & $\mathrm{x} \pm \mathrm{SD}$ & \\
\hline Week 1 \pm SD & $249.25 \pm 16.68$ & $219.25 \pm 24.02$ & 0.051 \\
Week 2 & $239.75 \pm 13.07$ & $235.62 \pm 28.01$ & 0.789 \\
Week 4 & $249.25 \pm 24.58$ & $229.38 \pm 27.66$ & 0.253 \\
Week 8 & $250.75 \pm 22.69$ & $240.75 \pm 29.08$ & 0.563 \\
Week 12 & $248.75 \pm 13.04$ & $243.25 \pm 25.62$ & 0.699 \\
\hline
\end{tabular}

In Table $7 \mathrm{a}$, shows that no remains of lens cortex fragments during cataract surgery with phacoemulsification. In Table $7 b$, based on the $T$ test $p=0.051 \quad(p>0.05)^{\prime} p=0.789$ $(p>0.05) ; p=0.253 \quad(p>0.05) ; p=0.563 \quad(p>0.05) ; p=0.699 \quad(p>0.05)$ showed there's no significant difference in the mean of macula thickness between the remains of lens cortex 
fragments and no remains of lens cortex fragments in the week 1,2,4,8, and 12 after the ECCE surgery.

\section{Discussion}

In this study,cystoid macular edema $(C M E)$ is not found after the cataract surgery.The pathogenesis of CME is still unclear (Flach, 1998). Likewise,inflammation of the anterior chamber is not found after the cataract surgery. The possibility of not finding inflammation after cataract surgery in this study was due to the preoperative administration of NSAID (diclofenac sodium 1\%) eye drops and postoperative corticosteroid eye drops. A study by Flach et al (1998) which compared the effect of $0.5 \%$ ketorolac eye drops with $0.1 \%$ diclofenac on inflammation after cataract surgery reported that both eye drops were equally effective and safe for controlling inflammation after cataract surgery and IOL implantation.

Other risk factors for CME after cataract surgery are tearing of the posterior capsule, loss of the vitreous and adhesion of the vitreous to the incision. The Percival (1998) reported that the presence of vitreous in COA caused the emergence of CME by 33\%. In this study, there was no posterior capsule tear in cataract surgery.

The location of the IOL affects the incidence of CME after cataract surgery. Flach (1998) states that the incidence of post-cataract CME surgery is higher in cataract surgery with iris clip IOL than anterior chamber dan posterior chamber IOL. The anterior chamber IOL is more at risk of increasing the incidence of CME than the posterior chamber (Flach, 1998). In this study, shows that based on the location of the IOL, all of the patients who underwent cataract surgery using the phacoemulsification technique and ECCE technique, all IOLs were located in the posterior chamber.

Types of cataract surgery are associated with different surgical outcomes and complications such as CME. The procedure changed from large incision intracapsular cataract extraction to extracapsular cataract extraction to phacoemulsification is associated with a decreased incidence of CME. This can be explained by the reduction in the damage to the blood aquous barrier after phacoemulsification with intact continuous curvilinear capsulorhexis compared to after extracapsular cataract extraction (Lobo, 2011). 
The study by Scheufele (2005) reported CME angiography in 1\% - 6\% of patients following uncomplicated phacoemulsification surgery. The risk of developing CME after cataract surgery is lower in phacoemulsification than ECCE due to decreased postoperative inflammation. Complications from posterior capsule tears were associated with clinical CME in $11.5 \%-20 \%$ for phacoemulsification surgery and $30.8 \%$ for ECCE surgery. The presence of lens fragments increased the risk of clinical CME by $29 \%$ after phacoemulsification surgery.

Gulkilik et al (2006) reported CME in $70 \%$ of patients with iris trauma and $20 \%$ of patients without iris trauma. The remains of the lens cortex increased the risk of clinical CME by $29 \%$ after phacoemulsification. (Scheufele TA, 2005). The remains of the lens cortex is associated with an increased incidence of CME (Lobo, 2011).

Patient age is a debatable factor. Several authors have suggested an increased incidence of CME in elderly patients. (Lobo, 2011). There are no studies on the relationship between hypertension and the onset of CME after cataract surgery. Altintas et al (2011) reported a significant increase in macular thickness after phacoemulsification surgery in patients with diabetes mellitus.

\section{Conclusion}

- In this study, there was no CME after cataract surgery

- In this study, there was a significant difference in the mean macular thickness after cataract surgery based on the type of surgery, an increase in the mean macular thickness in ECCE cataract surgery with iris trauma and the remains of the lens cortex and there was no significant difference in the mean macular thickness. post cataract surgery based on age, history of hypertension and diabetes mellitus.

\section{References}

Ah Fat FG, Sharma MK, Majid MA, Yang YC. 1998. Vitreous loss during conversion from conventional extracapsular cataract extraction to phacoemulsification. J Cataract Refract Surg;24:801-5.

Altintas K, Coban P, Sonmez K, Koklu G. 2011. Central macular thickness changes in diabetic patients after phacoemulsification surgery. Eur J Ophthalmol; 10. 
American Academy of Ophthalmology. 2011-2012. Basic and clinical science course: Section 11 - Lens and cataract. San Fransisco: American Academy Opthalmology. p 193-5.

Flach AJ. 1998. The incidence, pathogenesis and treatment of cystoid macular edema following cataract surgery. Trans Am Ophthalmol Soc; 96:557-634.

Gulkilik G, Kocabora S, Taskapili M, Engin G. 2006. Cystoid macular edema after phacoemulsification: risk factors and effect on visual acuity. Can J Ophtalmol; 41:699703.

Jackson TL. 2008. Moorfields manual of ophthalmology: Medical retina. Philadelphia: Elsevier Limited. p 492.

Lobo C. 2011. Pseudophakic Cystoid Macular Edema. Ophthalmologica; 10:1-7.

Percival P. 1998. Clinical factors relating to cystoid macular edema after lens implantation. J Am Intraocul Implant Soc; 7: 43-45.

Rotsos TG, Moschos MM. 2008. Cystoid macular edema. London: Dove Medical Press Ltd. p 919-29.

Scheufele TA, Heier JS. 2005. Pseudophakic cystoid macular edema. Available at: crstoday.com/2005/08/CRST0805_12.php. 